\title{
Balancing complexity and feasibility in Mediterranean coastal food-web models: uncertainty and constraints
}

\author{
Giulia Prato ${ }^{1, *}$, Didier Gascuel $^{2}$, Audrey Valls ${ }^{3}$, Patrice Francour $^{1}$ \\ ${ }^{1}$ Université de Nice Sophia Antipolis, Faculté de Sciences, EA 4228 ECOMERS, 06108 Nice cedex 2, France \\ ${ }^{2}$ Université Européenne de Bretagne, UMR Agrocampus ouest/INRA Ecologie et Santé des Ecosystèmes, \\ 65 rue de Saint Brieuc, CS 84215, 35042 Rennes cedex, France \\ ${ }^{3}$ University of British Columbia, Fisheries Centre, Vancouver, British Columbia V6T1Z4, Canada
}

\begin{abstract}
Mass-balance trophic models (Ecopath and EcoTroph) are valuable tools that can be used to describe ecosystem structure and functioning, identify target species to be monitored, and allow comparisons of ecosystem states under different management options. Nevertheless, the Ecopath modelling approach is constrained by 2 major sources of uncertainty: model complexity and input data quality. We developed an approach for identifying the optimum model structure that considers trade-offs between feasibility, complexity, and uncertainty, using a Mediterranean coastal ecosystem as a case study. We began with an existing well-documented and good-quality food-web model comprising 41 functional groups at Port-Cros National Park, France. Based on this model, we assessed the effects of different aggregation choices, driven by a simplification of sampling effort, on the Ecopath and EcoTroph model outputs. We identified the functional groups in which imprecise biomass input significantly influenced the food-web model, and measured the relative effects on the ecosystem trophic structure and ecosystem maturity and complexity indices. A simplified model comprising 32 functional groups was identified as the best compromise between model complexity and reliability. High trophic level predators, abundant primary producers, and groups with a high biomass and/or diversified diet significantly influenced the model structure. We concluded that the collection of local and accurate biomass data, especially for the most influential functional groups we identified, should be a priority when developing food-web models for similar ecosystems. Our method enables simplified and standardized models, while considering both the feasibility and reliability of the Ecopath and EcoTroph applications for Mediterranean coastal ecosystems.
\end{abstract}

KEY WORDS: Aggregation - Uncertainty - Complexity · Trophic spectrum - Ecosystem indices · Biomass $\cdot$ Ecopath $\cdot$ EcoTroph $\cdot$ Mediterranean Sea

Resale or republication not permitted without written consent of the publisher

\section{INTRODUCTION}

With the oceans facing increasing impacts by humans, unravelling the complexity of marine ecosystem functioning and species interactions has gradually become a pressing necessity. Single species approaches are not sufficient to ensure a sustainable exploitation of marine resources (Botsford et al.
1997, Hofmann \& Powell 1998). Instead, ecosystembased approaches enable a deeper understanding of the consequences of human exploitation by considering the whole ecosystem, and assist managers in implementing the sustainable use of natural resources (Coll et al. 2013a).

The development of the ecosystem approach to fisheries has triggered an exponential growth of 
modelling tools worldwide (Plagányi 2007, EspinozaTenorio et al. 2012). Originally developed by Polovina (1984), Ecopath with Ecosim (EwE) (Christensen \& Pauly 1992, Walters et al. 1997, Christensen \& Walters 2004) is the most widely used approach to represent marine food webs. About 400 EwE models with different objectives and representing a wide variety of ecosystems worldwide have been published (Colléter et al. 2013), ranging from exploring foodweb interactions to computing ecosystem indicators useful for cross-system comparisons, as well as for assessing the impact of fishing or marine protected areas (MPAs) on the ecosystem (Pauly et al. 2000, Christensen \& Walters 2005, Guénette et al. 2014). Ecopath is a mass-balanced and species-based model in which species with similar life cycles and diets are aggregated into functional groups. The descriptive Ecopath model is the key initialization step in the EwE modelling process, from which further dynamic and spatial predictions can be simulated with Ecosim and Ecospace for policy scenario testing (Walters et al. 1997, 1999). EcoTroph, a trophodynamic model recently integrated as a plug-in in the EwE software (Gascuel 2005, Gascuel \& Pauly 2009, Gascuel et al. 2009, 2011), is based on the idea that an ecosystem can be represented by the distribution of its biomass across trophic levels (TLs), called the biomass trophic spectrum. The simplified picture of ecosystem functioning provided by EcoTroph has proven to be very useful for exploring theoretical aspects of ecosystems, as well as for analysing the impacts of fishing or protection (Colléter et al. 2012, Gasche \& Gascuel 2013).

The use of ecosystem models such as the EwE model is generally constrained by 2 major sources of uncertainty: (1) structural complexity (Abarca-Arenas \& Ulanowicz 2002, Fulton et al. 2003, Pinnegar et al. 2005, Johnson et al. 2009), and (2) the amount and quality of the input data (Essington 2007, Link 2010, Fulton 2010, Kearney et al. 2013, Lassalle et al. 2014). Structural complexity in Ecopath models is measured as the number of compartments in the model, the way species are aggregated in these compartments, and the inclusion of stanzas, i.e. groups representing different life history stages for species that have a complex trophic ontogeny. In fact, it is unrealistic to include all interactions at the species level in a food web model. Moreover, adding complexity does not necessarily improve a model's performance, but generally increases uncertainty (Fulton et al. 2003). Species aggregation is thus necessary, but can strongly influence the model outputs. The over-aggregation of certain components of the food web, at either the upper or lower trophic levels, produces models with very different behaviours (Pinnegar et al. 2005) and has sometimes led to dissimilar and conflicting recommendations for management action (Punt \& Butterworth 1995, Yodzis 2001). In addition, Ecopath models require a large amount of input data, the quality of which can vary significantly. An in-depth evaluation of the sensitivity of Ecopath models to imprecise input data showed that the Ecopath modelling process is most sensitive to biomass and production rate parameters, and only occasionally sensitive to consumption rate and diet (Essington 2007). In our analysis, we decided to focus on the biomass input parameter. Biomass is of direct relevance to marine resource management, yet it is not easy to estimate accurately for the totality of the food web components due to the costs and constraints of sampling in the marine environment.

In the Mediterranean Sea, several Ecopath models have been built with various levels of detail, depending on the research questions and data availability (Table 1). For some exploited ecosystems (e.g. Northern Adriatic Sea, South Catalan Sea, Northern Aegean Sea, and Greek Ionian Sea), rather comprehensive models have been developed that include more than 30 functional groups based on the high availability of biomass data from industrial fishing monitoring (experimental trawling) (Table 1). In contrast, few models (e.g. Libralato et al. 2006, Albouy et al. 2010, Valls et al. 2012) representing coastal zones in the Mediterranean Sea have been developed and used to analyse MPAs (Table 1). The scarcity of foodweb models for the Mediterranean coastal MPAs is likely due to the high diversity and complexity of their food webs (Sala 2004), and the many challenges in terms of data collection. A protected area is a zone in which fishing and other human impacts are restricted to achieve conservation objectives. Thus, destructive sampling methods such as experimental fishing (i.e. trawl surveys), which could provide extensive data on the studied ecosystem, are generally prohibited or limited. However, less destructive methods also have limitations. Underwater monitoring techniques, such as visual censusing to assess fish and mega-invertebrate biomass or suction pumps to sample macrofauna, are time consuming and require a considerable workload for collecting the samples in the field and analysing them at the laboratory. Thus, field-based estimates of biomass are generally available only for a subset of species of recognized ecological importance in coastal zones and/or of particular management relevance in protected areas. For instance, in the Mediterranean, 


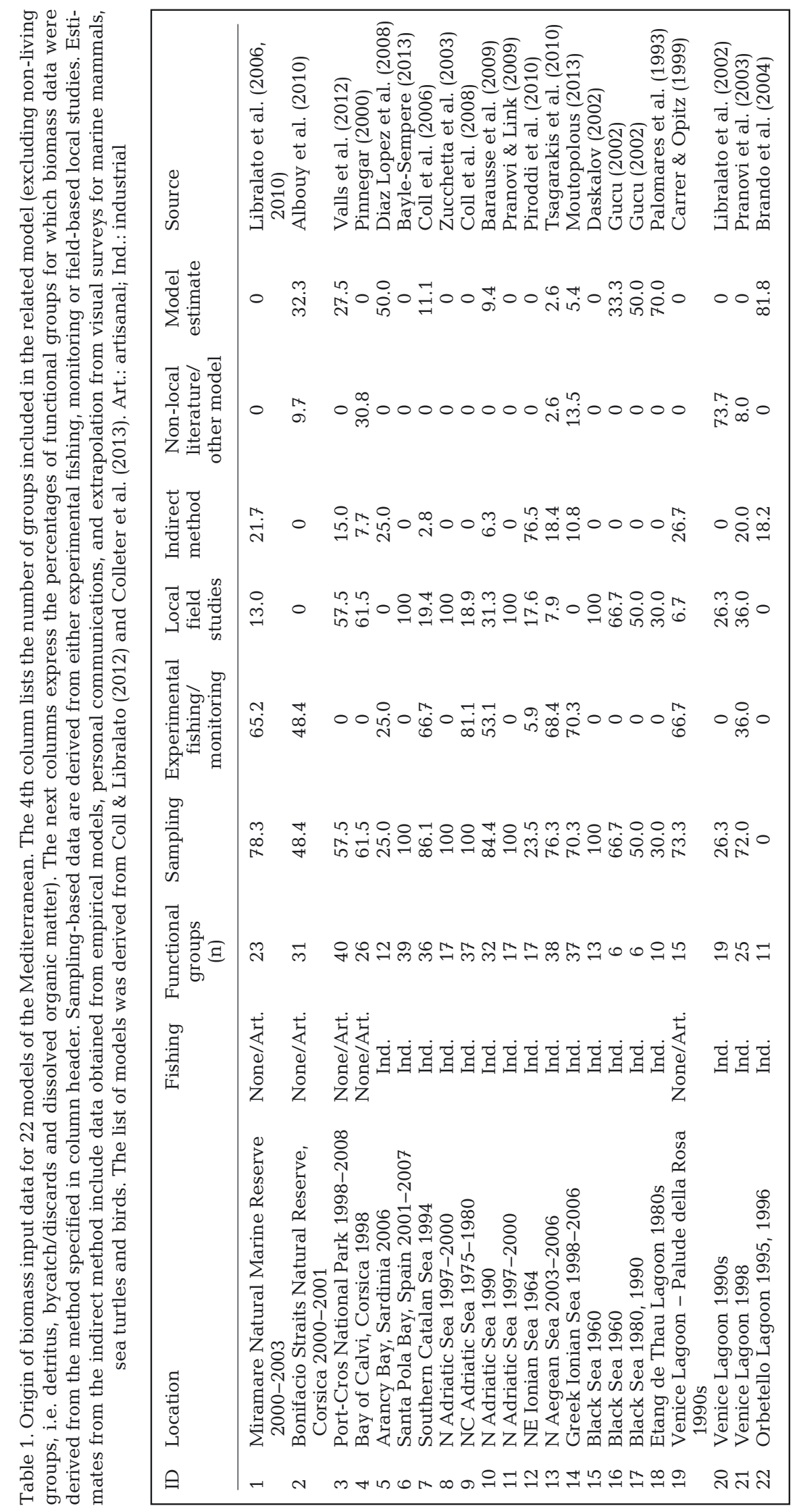

there is extensive knowledge on the trophic interactions between sea bream, sea urchins, and macroalgae and their role in controlling coastal ecosystem states (Sala et al. 1998, Guidetti 2007). These groups are thus common monitoring targets in Mediterranean MPAs, while we face a lack of data and knowledge for many other functional groups (Sala 2004). Consequently, the application of food-web modelling has remained relatively limited in coastal Mediterranean ecosystems.

The objective of this work was to determine an optimum and standardized model structure to represent a northwestern Mediterranean coastal food web that accounts for the trade-offs between feasibility, complexity, and uncertainty. To do so, we selected the Ecopath model representing the MPA of Port-Cros, a French marine national park in the northwestern Mediterranean Sea (Valls et al. 2012). This model was originally built to synthesize all available data and identify knowledge gaps regarding the described ecosystem. Thus, the study presents detailed information on species aggregation into the 41 defined functional groups (Table 2), which makes it the most detailed model available representing a Mediterranean coastal food web (Table 1). Such a comprehensive synthesis was made possible by the many years of research and monitoring that produced a significant amount of data for this old MPA, created in 1963 (e.g. Khoury 1987, Francour 1990). Hence, the biomass parameters were estimated from local field-based studies for $57.5 \%$ of the functional groups, which is a relatively high score compared to similar modelled ecosystems (Table 1). We used the original Port-Cros model as our control state, and we simplified its trophic structure by applying different levels of species aggregation, the choice of which was driven by sampling feasibility con- 
Table 2. The 41 functional groups of the Port-Cros control model. Details in Valls et al. (2012). Only the least destructive methods were considered: visual survey (VS), visual census (VC), acoustics (Ac), suction sampler (SS), scraping (SC), plankton nets/bottles (PNB), chlorophyll remote sensing (CRS), corer (Co), and net fishing (NF). The groups in bold are those considered for aggregation

\begin{tabular}{|ll|}
\hline Sampling method & Functional group \\
\hline VS & Seabirds \\
VC & Amberjack+ \\
VC & Dusky grouper - medium \\
VC & Dusky grouper - large \\
VC & Dusky grouper - small \\
VC, NF & Rays \\
VC, NF & Large-scaled scorpionfish+ \\
VC, NF & Scorpionfishes+ \\
VC, NF & Striped red mullet+ \\
VC, NF & Pagellus \\
VC, AC, NF & Horse mackerels+ \\
VC, NF & Diplodus+ \\
VC, NF & Wrasses \\
VC, NF & Mullets \\
VC, C & Cephalopods \\
VC, SS & Blennies \\
VC, SS & Pipefishes+ \\
VC, SS & Gobies \\
SS, SC & Gastropods \\
SS & Small crustaceans \\
SS & Amphipods \\
SS & Brittle stars+ \\
SS, SC & Suspensivores \\
SS, VC & Crabs \\
SS, VC & Decapods \\
SS, Co, SC & Polychaetes \\
SS, VC, SC & Bivalves \\
VC & Sea stars \\
VC & Sea cucumbers \\
VC & Sea urchins \\
PNB & Large zooplankton \\
PNB & Small zooplankton \\
VC & Gorgonians \\
VC, NF & Salema - adults \\
VC & Salema - juveniles \\
Co, SC & Foraminifera \\
A, SC & Posidonia \\
SC & Shallow seaweeds \\
SC & Deep seaweeds \\
PNB, CRS & Phytoplankton \\
Co, SS & Detritus \\
\hline
\end{tabular}

siderations. We then identified the functional groups for which local and accurate biomass data should be collected as a priority, as they have the most significant influence on the model outputs. Specifically, we focused on 3 main questions: (1) how do samplingdriven aggregation choices alter the model description of ecosystem functioning; (2) to what level of aggregation can the model be simplified without sig- nificantly altering its accuracy; and (3) what are the functional groups in the simplified model for which imprecise biomass input significantly influences the biomass calculations of other groups, and thus the overall description of the ecosystem functioning.

By addressing these issues, we intended to propose some priority guidelines, in terms of model structure and data collection, that could enable the development of standardized models of complex Mediterranean coastal ecosystems.

\section{METHODS}

Two food-web modelling approaches were used in our analysis: the species-based Ecopath model and the TL-based EcoTroph model. Ecopath was used to build several versions based on the control model, with different levels of aggregation and different input biomass values, while EcoTroph was used to compute the trophic spectra for each new model. Sensitivity analyses were performed on selected ecosystem maturity and complexity indices computed by Ecopath, and on the trophic description of the ecosystem provided by EcoTroph.

\section{Ecopath}

Ecopath uses a mass-balanced food-web model, assuming that the production of one functional group is equal to the sum of all predation, non-predatory losses, exports, biomass accumulations, and catches, as expressed by the following equation:

$$
\begin{aligned}
P / B_{i} \times B_{i} & =P / B_{i} \times B_{i} \times\left(1-E E_{i}\right) \\
& +\Sigma j(Q / B)_{j i} \times B_{i} \times D C_{j i}+Y_{i}+N M_{i}+B A_{i}
\end{aligned}
$$

where $B$ is the biomass, $P / B_{\mathrm{i}}$ is the production rate, $Q / B$ is the consumption rate, $D C_{j i}$ is the diet composition representing the fraction of prey $i$ in the diet of predator $j, N M_{i}$ is the net migration of prey $i, B A_{i}$ is the biomass accumulation of prey $i, Y_{i}$ is the catch of prey $i$, and $E E_{\mathrm{i}}$ is the ecotrophic efficiency of prey $i$ (the proportion of production that is used in the system, e.g. through predation and harvest). Assuming there is no export and no biomass accumulation, and the catches are known, only 3 of the 4 remaining parameters $\left(B, P / B_{i}, Q / B\right.$, and $\left.E E_{i}\right)$ have to be set initially for each group. The parameterization routine solves the equations for each missing parameter iteratively (Christensen et al. 2008).

A comprehensive Ecopath model was built by Valls et al. (2012) for the Port-Cros MPA (Table 2), which 
covers a surface area of $13 \mathrm{~km}^{2}$ and reaches a maximum depth of $50 \mathrm{~m}$. Biotopes are typical of the northwestern Mediterranean, with nearshore rocky reefs, large Posidonia oceanica meadows, and a coralligenous habitat, hosting a high biodiversity of commercially important fish and decapod crustaceans; only $5 \%$ of the reserve is a no-take area, outside of which fishing is permitted with severe restrictions (Francour et al. 2001). The Ecopath model represents an average situation for the period from 1998 to 2008, defined by the data used in the model. Large amounts of data were available for this old and well-studied MPA, which allowed for the development of a relatively detailed model, including 40 living functional groups (plus one detrital group). More precisely, the model comprises 18 groups of fish, 17 groups of invertebrates, 4 groups of primary producers, and 1 group of seabirds. In addition, the model is well documented in terms of both species aggregation choices and species-level information for each functional group. Moreover, all fish biomass data are of good quality as they were derived from visual censusing and scientific trawling in the area. Local fieldbased biomass data were also available for some invertebrate and primary producer groups. Details on the species composition of each functional group in the control Port-Cros model, as well as the input parameters for each group, can be found in Valls et al. (2012). Finally, the model respected Link's recommendations of data quality (Link 2010), and its representation of the Port-Cros ecosystem was in accordance with the current available knowledge (Valls et al. 2012).

\section{EcoTroph}

The trophic level-based EcoTroph model assumes that biomass has a continuous distribution in an ecosystem as a function of continuous TLs. The biomass is represented as entering the system at $\mathrm{TL}=1$, generated by the photosynthetic activity of primary producers or recycled from the detritus by the microbial loop. Then, at TLs $>2$, the biomass is distributed along a continuum of TL values and all fractional TLs are filled due to the diet variability of the various consumers. The resulting biomass distribution constitutes the biomass trophic spectrum (Gascuel et al. 2005). The functioning of the ecosystem is then modelled as a continuous flow of biomass, surging up the food web from lower to higher TLs, through predation and ontogenic processes.
Based on the usual equations of fluid dynamics, the flow of the biomass present in the ecosystem at TL $\tau$ under steady-state conditions is expressed as:

$$
\varphi(\tau)=D(\tau) \times K(\tau)
$$

where $\varphi(\tau)$ refers to the amount of biomass that moves up the food web through TL $\tau$ (metric $t$ per year), $D(\tau)$ is the density of biomass at TL $\tau$ (metric $t$ per trophic level), and $K(\tau)$ is the speed of flow, which quantifies the velocity of biomass transfers in the food web (number of TLs crossed per year).

The continuous distribution of the biomass across a TL is calculated using a discrete approximation based on small trophic classes. EcoTroph conventionally considers trophic classes of width $\Delta \tau$ equal to 0.1 TL, from TL 2 (corresponding to first-order consumers) to TL 5 (a value considered sufficient to cover all top predators likely to occur in marine ecosystems). Thus, the mean biomass $B_{\tau}$ (in metric $\mathrm{t}$ ), which is present in the $[\tau, \tau+\Delta \tau]$ trophic class under steady-state conditions, can be estimated as $\int D(\tau) \times$ $\mathrm{d} \tau$ or $D(\tau) \times \Delta \tau$ for a small interval $\Delta \tau$. Therefore,

$$
B_{\tau}=\varphi_{\tau} \times \Delta_{\tau} / K_{\tau}
$$

where $\varphi_{\tau}$ and $K_{\tau}$ are the mean biomass flow and mean speed of flow within the $[\tau, \tau+\Delta \tau]$ trophic class, respectively; see the supplementary material in Valls et al. (2012) for further explanation.

In this study, we used the ET-Transpose routine described in Gascuel et al. (2009) to translate the outputs of the original Ecopath model into an EcoTroph model and to build the biomass trophic spectrum. The biomass of each functional Ecopath group was distributed over a range of trophic classes around the mean TL of the group (estimated by Ecopath), assuming a log-normal distribution. The trophic spectrum is the curve obtained by summing the biomass parameter over all functional groups and provides a synthetic view of the trophic structure of the ecosystem.

We then used the ET-Diagnosis routine to conduct sensitivity testing. We simulated how the baseline ecosystem would be impacted by increasing or decreasing the fishing effort. Fishing effort can be modified per fleet by applying various effort multipliers, and the structure of the trophic spectrum will vary under different efforts (Gascuel et al. 2011, Gasche \& Gascuel 2013).

\section{Aggregated models and comparisons}

The original version of the Ecopath model for the Port-Cros National Park's MPA, described by Valls et 
al. (2012), was selected as the control model in our simplification procedure, and 6 models were derived from this, using successive aggregation steps. Purely taxonomical aggregations were avoided. Aggregation choices were driven by sampling efficiency considerations; for each functional group, the most adequate and least destructive sampling methods were assigned, and groups that shared at least one common sampling method were considered for aggregation. Thus, aggregation choices were also consistent with the habitat use among groups, so that species in the same group occupied the same habitat. Aggregation choices were also constrained by diet composition overlap and similarities in production and consumption ( $P / B$ and $Q / B$ rates), which should differ by less than 3-fold between groups (Fulton et al. 2003). Small cryptobenthic fish (blennies, pipefishes, and gobies) were grouped based on the difficulty in sampling them and because they share similar lifehistory parameters. The other fish functional groups were not further aggregated relative to the original model, in which they were grouped according to their TL, maximum length, and feeding type (Valls et al. 2012).

Starting from the first aggregated model (the one with the broadest aggregation of the invertebrate groups), a biomass trophic spectrum was computed, and the trophic spectra ratios between this first model and the control were compared. The TLs corresponding to the widest changes in the trophic spectrum were identified, and the corresponding functional groups were isolated in the subsequent model, in which different levels of aggregation were tested. For each new model, static ecosystem indices were computed and the percentage difference between each aggregated model and the control were compared. This procedure was repeated stepwise until the aggregation with the fewest differences from the control in the trophic spectra and ecosystem indices was identified. $P / B$ and $Q / B$ ratios were computed for the newly aggregated groups; they were weighted with the biomass and summed over all of the groups to be aggregated. Similarly, the new diet compositions were obtained by weighting the food intake of each group with the consumption of the group, and then summing the food intakes over all of the groups to be aggregated.

To evaluate the successive species aggregations, we compared the ecosystem indices that are most widely accepted as indicators of ecosystem maturity and complexity in the literature: Finn's cycling index (FCI), system omnivory index (SOI), relative ascendency $(\% \mathrm{~A})$, and $\mathrm{TL}$ of the community $\left(\mathrm{TL}_{\mathrm{co}}\right)($ Chris- tensen 1995, Libralato et al. 2010). Because the total amount of matter flowing in each model was maintained constant and equal to the original, the maturity indices related to the flows and biomasses were not considered. FCI measures the fraction of the ecosystem's throughput that is recycled. The degree of energy and nutrient recycling in an ecosystem is assumed to increase as ecosystems mature and develop routes for nutrient conservation (Odum 1969). SOI is defined as the average omnivory index of all consumers, weighted by the logarithm of the food intakes (Christensen \& Pauly 1992). It expresses the variance in the TLs of the consumers' prey groups (Pauly et al. 1993) and is considered a measure of food-web complexity. Ascendency is a measure of the average mutual information in a system, scaled by system throughput, and is derived from information theory (Ulanowicz \& Norden 1990). If one knows the location of a unit of energy, the uncertainty about where it will flow to next is reduced by an amount known as the 'average mutual information'. The amount of the average mutual information multiplied by the total system throughput (TST) gives the ascendancy (A). There is an upper limit for the development of the ascendancy, which is called the 'development capacity'. Here, we are considering \%A, defined as the ratio between $\mathrm{A}$ and the development capacity that was demonstrated to be clearly correlated with maturity sensu Odum (Christensen 1994). The average $\mathrm{TL}_{\mathrm{co}}$ is estimated as the biomassweighted average TL for all functional groups of the web, excluding those at TL $=1$. Libralato et al. (2010) showed that $\mathrm{TL}_{\text {со }}$ was consistently lower in a fished food web compared to an adjacent unexploited one. Given the similarity of fishing patterns in coastal Mediterranean waters, we retained $\mathrm{TL}_{\mathrm{co}}$ as a good indicator of the fishing effects.

The model that showed the smallest differences from the control in the trophic spectra and ecosystem indices was considered to offer the best species aggregation scheme, and was therefore selected for further analysis. The ET-Diagnosis function was applied to test whether the selected model would behave differently from the control in terms of assessing the fishing impact on the ecosystem. For both the control and the selected model, we built 2 different fishing scenarios by applying 2 effort multipliers $(m F)$ to the current fishing mortality of each trophic class. Specifically, we applied an $m F=0$ to simulate a closure of the fishery and an $m F=12$ to simulate an increase in fishing effort. The latter value of $m F$ was shown to be of the same order of magnitude as those observed in surrounding and similar 
unprotected areas (Valls et al. 2012). We then compared the simulation outputs to the unexploited state and identified the differences between the patterns of the 2 models.

\section{Sensitivity to error in input biomass and identification of the most influential species}

The model selected after aggregation was set as the new reference (ref. model) to test the effects of variation in each group's input biomass on the biomass estimates of the other groups, and to evaluate the impact of these errors on the overall model outputs; 31 new models were built by increasing the biomass of each group by $10 \%$ and obtaining the biomass of the other groups (except primary producers) from the Ecopath equation solutions (with ecotrophic efficiencies fixed). During this process, the biomass of the primary producers was not obtained from the Ecopath equation solutions, but instead was kept at its original value, because it was input data in the original model and therefore avoided a potential modelling artefact: i.e. strong increases in primary producer biomass to sustain increased consumer abundance due to the Ecopath routine estimation of the primary production required to sustain consumption. Thus, we were conservative by evaluating the minimum impact that imprecise input biomass for consumers would have on the model outputs. Subsequently, the biomass of each primary producer was also varied by $10 \%$, and the biomasses of all other groups were obtained from the Ecopath equation solutions to test the influence of an error in the primary producer input biomass.

A variation of $10 \%$ was assumed to be small enough to keep the models mass-balanced and large enough to create differences between the models. To test the model sensitivity to the biomass increments, the biomass trophic spectra and maturity indices were compared between each new model and the ref. model. The trophic spectra of the ratios between the new model and the ref. model were plotted, and 3 indices were derived: the number of trophic levels affected by a variation in the biomass of $>1 \%$ (i.e. the width of the trophic spectra, Width_TS); the maximum level of biomass increase (i.e. the peak of the trophic spectra, Peak_TS), and the total biomass increase (i.e. the area of the trophic spectra, B_TS); the latter was expressed as the percentage difference from the ref. model biomass and was increased for several functional groups simultaneously to test for any amplifying effect on the trophic spectra. The percentage differences from the ref. model were compared for $\%$ A, SOI, FCI, $\mathrm{TL}_{\mathrm{co}}$, and 2 additional flow indices: the ratio of total primary production to total respiration (TPP/R) and the ratio of total biomass to total system throughput (B/TST). The latter 2 flow-related maturity indices were included at this step of the analysis because variations in the functional groups' biomass inputs induced variations in the amount of matter flowing in the model.

A principal component analysis (PCA) was conducted to visualize the impact of each functional group on the ecosystem attributes. The previously mentioned indices of maturity, complexity, and trophic structure were the explicative variables of the PCA, while the different models obtained by $10 \%$ increases in the biomass of each functional group were the samples. All variables were standardized to a zero mean and unit variance to compensate for differences in the value ranges. TL and biomass were included in the PCA as supplementary continuous variables and trophic class was included as a supplementary categorical variable, so that they would not be considered in the computation of the principal components. The groups were then ranked according to their contribution to each of the first 3 principal components, and their mean ranking was computed. Thus, summarized information was obtained for the functional groups with the most impact on the variables overall. The functional groups were then plotted in decreasing order of their mean rank (a rank of 1 was attributed to the group having the greatest impact). The groups with the highest rankings were identified and selected as those having the most impact on the model's output, and thus requiring local and accurate biomass input data.

\section{RESULTS}

\section{Model aggregations and comparisons}

Model A included 33 living groups (Table 3) and was characterized by the largest aggregation of invertebrate groups that can be sampled with suction devices (gastropods, small crustaceans, amphipods, brittle stars, suspensivores, crabs, decapods, and polychaetes comprised a new Epifauna+ group). Sea stars and sea cucumbers were not included, because their constant production and consumption rates differ significantly from the other invertebrates, and estimates of their biomass are more commonly obtained from a visual census. Model B (34 living groups) differed from Model A by the separation of a 
Table 3. Aggregation schemes. The groups that were not modified from the control model are not listed. Number of functional groups (excluding detritus) given at bottom. Grey boxes indicate functional groups that have been mapped to an aggregate group listed higher in the table. Co: corer; SC: scraping; SS: suction sampler; VC: visual census

\begin{tabular}{|c|c|c|c|c|c|c|c|}
\hline Sampling & Control & Model A & Model B & Model C & Model D & Model E & Model F \\
\hline VC, SS & Blennies & Blennies & Blennies & \multirow{2}{*}{$\begin{array}{l}\text { Blennies+ } \\
\text { (blennies, } \\
\text { pipefishes) }\end{array}$} & \multirow{2}{*}{$\begin{array}{l}\text { Blennies+ } \\
\text { (blennies, } \\
\text { pipefishes) }\end{array}$} & \multirow{2}{*}{$\begin{array}{l}\text { Blennies+ } \\
\text { (blennies, } \\
\text { pipefishes) }\end{array}$} & \multirow{3}{*}{$\begin{array}{l}\text { Gobies+ } \\
\text { (blennies, } \\
\text { pipefishes, } \\
\text { gobies) }\end{array}$} \\
\hline VC, SS & Pipefishes+ & Pipefishes+ & Pipefishes+ & & & & \\
\hline VC, SS & Gobies & Gobies & Gobies & Gobies & Gobies & Gobies & \\
\hline $\mathrm{SS}, \mathrm{SC}$ & Gastropods & \multirow{8}{*}{$\begin{array}{l}\text { Epifauna } \\
\text { (gastropods, } \\
\text { small } \\
\text { crustaceans, } \\
\text { amphipods, } \\
\text { brittle stars, } \\
\text { suspensivore, } \\
\text { crabs, } \\
\text { decapods, } \\
\text { polychaetes) }\end{array}$} & \multirow{5}{*}{$\begin{array}{l}\text { Epifauna } \\
\text { (gastropods, } \\
\text { small } \\
\text { crustaceans, } \\
\text { amphipods, } \\
\text { brittle stars, } \\
\text { suspensivore, } \\
\text { polychaetes) }\end{array}$} & \multirow{4}{*}{$\begin{array}{l}\text { Epifauna } \\
\text { (gastropods, } \\
\text { small } \\
\text { crustaceans, } \\
\text { amphipods, } \\
\text { brittle stars, } \\
\text { polychaetes) }\end{array}$} & \multirow{4}{*}{$\begin{array}{l}\text { Epifauna } \\
\text { (gastropods, } \\
\text { small } \\
\text { crustaceans, } \\
\text { amphipods, } \\
\text { brittle stars) }\end{array}$} & \multirow{5}{*}{$\begin{array}{l}\text { Epifauna } \\
\text { (gastropods, } \\
\text { small } \\
\text { crustaceans, } \\
\text { amphipods, } \\
\text { brittle stars, } \\
\text { suspensivore, } \\
\text { bivalves) }\end{array}$} & \multirow{4}{*}{$\begin{array}{l}\text { Epifauna } \\
\text { (gastropods, } \\
\text { small } \\
\text { crustaceans, } \\
\text { amphipods, } \\
\text { brittle stars) }\end{array}$} \\
\hline SS & $\begin{array}{l}\text { Small } \\
\text { crustaceans }\end{array}$ & & & & & & \\
\hline SS & Amphipods & & & & & & \\
\hline SS & Brittle stars+ & & & & & & \\
\hline $\mathrm{SS}, \mathrm{SC}$ & Suspensivores & & & $\begin{array}{l}\text { Suspensivores+ } \\
\text { (bivalves, } \\
\text { suspensivores) }\end{array}$ & $\begin{array}{l}\text { Suspensivores+ } \\
\text { (bivalves, } \\
\text { suspensivores) }\end{array}$ & & $\begin{array}{l}\text { Suspensivores+ } \\
\text { (bivalves, } \\
\text { suspensivores) }\end{array}$ \\
\hline $\mathrm{SS}, \mathrm{VC}$ & Crabs & & \multirow{3}{*}{$\begin{array}{l}\text { Decapods+ } \\
\text { (crabs, } \\
\text { decapods) }\end{array}$} & \multirow{3}{*}{$\begin{array}{l}\text { Decapods+ } \\
\text { (crabs, } \\
\text { decapods) }\end{array}$} & \multirow{2}{*}{$\begin{array}{l}\text { Decapods+ } \\
\text { (crabs, } \\
\text { decapods) }\end{array}$} & \multirow{2}{*}{$\begin{array}{l}\text { Decapods+ } \\
\text { (crabs, } \\
\text { decapods) }\end{array}$} & \multirow{2}{*}{$\begin{array}{l}\text { Decapods+ } \\
\text { (crabs, } \\
\text { decapods) }\end{array}$} \\
\hline $\mathrm{SS}, \mathrm{VC}$ & Decapods & & & & & & \\
\hline $\mathrm{SS}, \mathrm{Co}, \mathrm{SC}$ & Polychaetes & & & & Polychaetes & Polychaetes & Polychaetes \\
\hline $\mathrm{SS}, \mathrm{VC}, \mathrm{SC}$ & Bivalves & Bivalves & Bivalves & & & & \\
\hline $\mathrm{VC}$ & Sea stars & Sea stars & Sea stars & \multirow{2}{*}{$\begin{array}{l}\text { Echinoderms+ } \\
\text { (sea stars, sea } \\
\text { cucumbers) }\end{array}$} & \multirow{2}{*}{$\begin{array}{l}\text { Echinoderms+ } \\
\text { (sea stars, sea } \\
\text { cucumbers) }\end{array}$} & \multirow{2}{*}{$\begin{array}{l}\text { Echinoderm+ } \\
\text { (sea stars, sea } \\
\text { cucumbers) }\end{array}$} & \multirow{2}{*}{$\begin{array}{l}\text { Echinoderms+ } \\
\text { (sea stars, sea } \\
\text { cucumbers) }\end{array}$} \\
\hline $\mathrm{VC}$ & Sea cucumbers & Sea cucumbers & Sea cucumbers & & & & \\
\hline $\mathrm{SC}$ & $\begin{array}{l}\text { Shallow } \\
\text { seaweeds }\end{array}$ & $\begin{array}{l}\text { Shallow } \\
\text { seaweeds }\end{array}$ & $\begin{array}{l}\text { Shallow } \\
\text { seaweeds }\end{array}$ & \multirow{2}{*}{$\begin{array}{l}\text { Seaweeds+ } \\
\text { (shallow } \\
\text { seaweeds, } \\
\text { deep } \\
\text { seaweeds) }\end{array}$} & \multirow{2}{*}{$\begin{array}{l}\text { Seaweeds+ } \\
\text { (shallow } \\
\text { seaweeds, } \\
\text { deep } \\
\text { seaweeds) }\end{array}$} & \multirow{2}{*}{$\begin{array}{l}\text { Seaweeds+ } \\
\text { (shallow } \\
\text { seaweeds, } \\
\text { deep } \\
\text { seaweeds) }\end{array}$} & \multirow{2}{*}{$\begin{array}{l}\text { Seaweeds+ } \\
\text { (shallow } \\
\text { seaweeds, } \\
\text { deep } \\
\text { seaweeds) }\end{array}$} \\
\hline $\mathrm{SC}$ & $\begin{array}{l}\text { Deep } \\
\text { seaweeds }\end{array}$ & $\begin{array}{l}\text { Deep } \\
\text { seaweeds }\end{array}$ & $\begin{array}{l}\text { Deep } \\
\text { seaweeds }\end{array}$ & & & & \\
\hline $\begin{array}{l}\text { No. of } \\
\text { groups }\end{array}$ & 40 & 33 & 34 & 31 & 32 & 31 & 31 \\
\hline
\end{tabular}

pooled crab and decapod group (Decapods+) from the Epifauna+ group. In Model $\mathrm{C}$, suspensivores were excluded from the Epifauna+ group as well, and aggregated with bivalves (Suspensivores+). Moreover, sea stars were grouped with sea cucumbers (Echinoderms+), blennies with pipefishes (Blennies+), and shallow seaweeds with deep seaweeds (Seaweeds+), resulting in an overall aggregation into 31 living groups. Model D (32 living groups) was equal to Model $\mathrm{C}$, except for the polychaetes, which were excluded from the Epifauna+ group and defined as a separate group. In Model E (31 living groups), the suspensivores and bivalves were added to the Epifauna+ group, while the polychaetes were kept separated. Finally, Model F (31 living groups) was characterized by an Epifauna+ group that included gastropods, small crustaceans, amphipods, and brittle stars. The previously defined groups of Decapods+, Suspensivores+, Echinoderms+, and Seaweeds+ remained as separate groups, while a Gobies+ group was created to aggregate gobies, blennies, and pipefishes.

For every aggregated model, FCI and \%A were higher than in the control model, while the SOI was systematically lower. The differences in $\mathrm{TL}_{\mathrm{co}}$ were either negative or null. The aggregation that caused the largest variations in ecosystem indices (Fig. 1) and trophic spectra (Fig. 2) was that of crabs and decapods with Epifaunat (Model A), causing a $30 \%$ increase in FCI (Fig. 1) and negative biomass differences for TL $>3.5$ (Fig. 2a). Suspensivores+ and polychaetes also significantly affected ecosystem indices and trophic spectra when aggregated with the Epifauna+ group; Mod- 


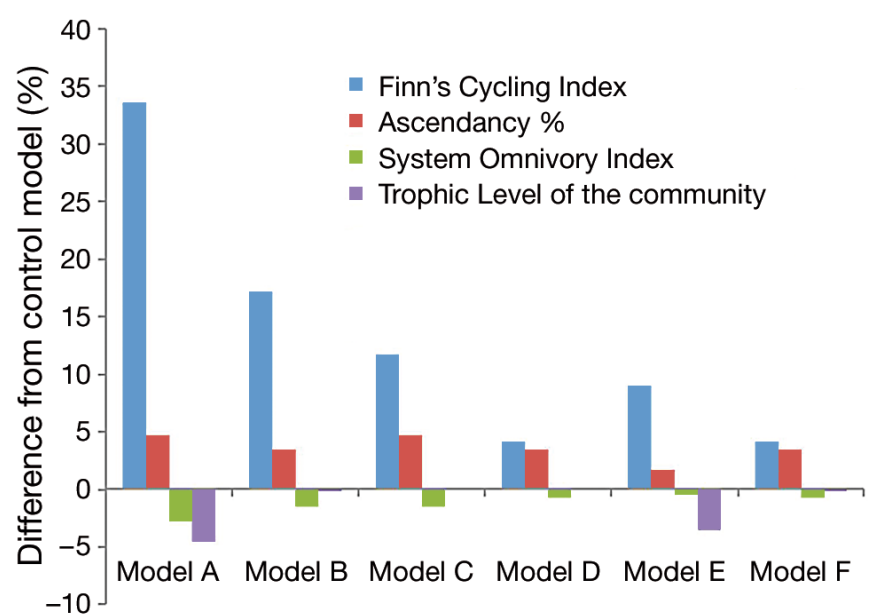

Fig. 1. Percentage differences in the system indices between the aggregated models and the control model

els $\mathrm{D}$ and $\mathrm{F}$ showed the least differences from the control (Figs. 1 \& 2b). The aggregations of Echinoderms, Seaweeds+ and Gobies+ caused no major modifications in model properties. Model F, with 31 living functional groups, had the most simplified species aggregation scheme, i.e. the smallest variations in the ecosystem indices and trophic structure relative to the control for the highest level of species aggregation possible.

The simulation test confirmed that the behaviour of Model F was similar to that of the control, when both closure $(m F=0)$ and increased fishing effort $(m F=$ 12) were simulated. The exploitation effect was significant only at TL $>3.5$, and in neither the original nor the aggregated model did the exploitation cause major biomass variations at the lower TLs (Fig. 3). Model F was thus selected for successive analysis.

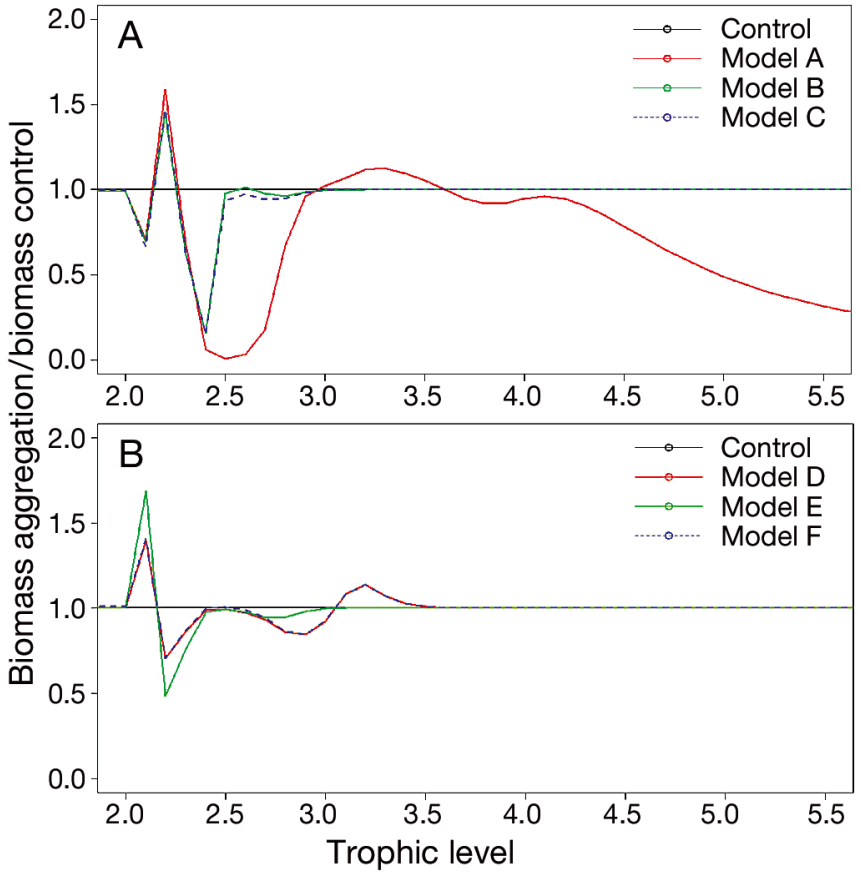

Fig. 2. Trophic spectra of the ratios of the biomass between the control model and (A) aggregated Models A, B, and C or

(B) aggregated Models D, E, and F, in relative values

groups affected the biomass of all other trophic groups by more than $1 \%$, with most TLs affected by more than $5 \%$ (Fig. 4A). The trophic spectra sensitivity to Dusky grouper - large increased when $\mathrm{TL} \geq 4$, since this was the only group occupying the highest TLs. The trophic spectra for both Amberjack+ and Dusky grouper - large reached peaks with an approximately $9 \%$ increase in biomass, and overall biomass increased (B_TS) by 0.25 and $0.28 \%$, respectively, relative to Model F. With regard to the other fish groups, the highest impact in terms of number of TLs affected and shifts in biomass was caused by

\section{Sensitivity to error in the input biomass}

A sensitivity analysis was applied to Model F. The analyses of the trophic spectra (Fig. 4) and the differences in the ecosystem indices due to biomass variations (see Appendix 1) showed that the high TL predator groups, Amberjack+ and Dusky grouper large, had the largest impacts on the biomass of the other groups, and thus most influenced the trophic spectra and ecosystem indices. Increments of $10 \%$ in the biomass of these 2 large fish

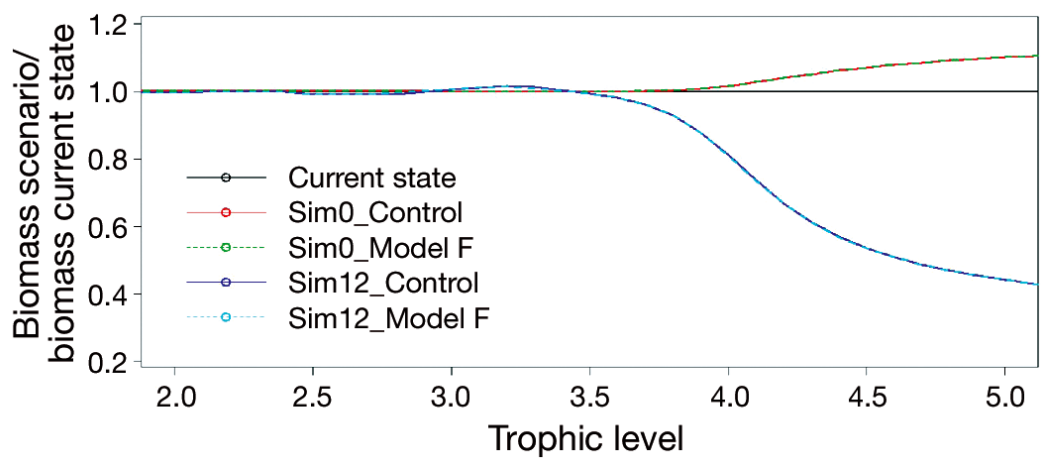

Fig. 3. Simulation scenarios for Model F and the control model. Relative biomass values were obtained from the trophic spectra ratios, with effort multipliers $m F=12(\operatorname{Sim} 12)$ and $m F=0(\operatorname{Sim} 0)$ applied to both models 

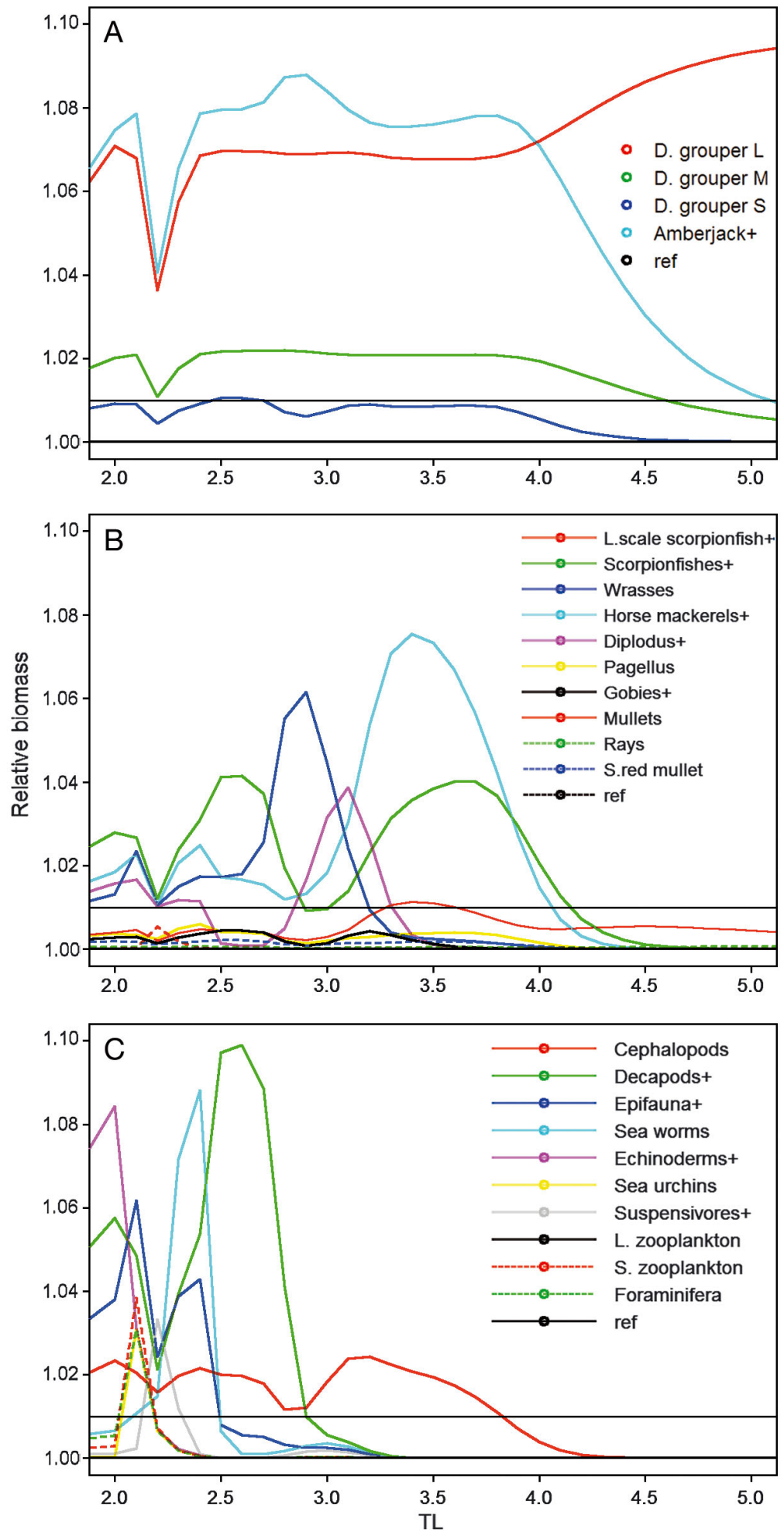

Fig. 4. Biomass ratios between the trophic spectra of each model obtained after an increase of $10 \%$ to the biomass of one functional group and the trophic spectra of the reference model (represented by the solid line at relative biomass $=1$ ). The dotted line corresponds to the threshold value of a $1 \%$ variation in biomass. (A) Higher trophic level predators; (B) other fish groups; (C) invertebrates
Horse mackerels + (Width_TS $=21$, Peak_TS $=7.5 \%$, B_TS $=0.09 \%$ ), followed by Scorpionfishes+ and Wrasses (Fig. 4B).

Among the invertebrates (Fig. 4C), Cephalopods+ affected the largest number of trophic levels (Width_TS $=19$ ), followed by Decapods (Width_TS $=9$ ). Decapods was the group with the most impact on the Peak_TS index; under their influence, the trophic spectrum reached the maximum peak resulting from a $10 \%$ increment in the biomass. An increase of $10 \%$ in the biomass of Sea worms and Echinoderms+ led to high biomass peaks in the trophic spectra $($ Peak_TS $=8.8$, Peak_TS $=8.4 \%$, respectively), but their impacts were limited to a very narrow range of TLs corresponding to their own range (Width_TS $=4$, Width_TS $=2$, respectively). A simultaneous biomass increase of several functional groups resulted in a simple additive effect on the trophic spectra and thus was not considered further.

Similar to the trophic spectra analysis, a $10 \%$ increment in the biomass of the Dusky grouper - large and Amberjack+ groups caused the largest variations in absolute terms in all ecosystem indices, especially impacting FCI (7.2 and $8.1 \%$, respectively), TPP/R (6.4 and $7.2 \%$, respectively), and \% A $(2.1 \%$ for both). As for the Epifaunat, Decapods+, Cephalopods, and Horse mackerels+ groups, the biomass increments caused large variations in FCI (max. value $=$ $7.0 \%$ for Epifauna + ) and SOI (max. value $=$ $1.6 \%$ for Horse mackerels+). Increments in the biomass of Foraminifera and Small zooplankton had a strong influence on FCI (6.3 and $6.6 \%$, respectively). Posidonia oceanica had a high overall impact and principally caused large variations in the flow indices TPP/R (4.7\%) and B/TST (6.1\%), and in \%A $(2.1 \%)$.

\section{Principal component analysis}

A PCA on all indices was performed (Fig. 5). The first PC accounted for almost $50 \%$ of the variability of the data, and the second PC accounted for $25 \%$ (Fig. 5A). The first PC summarized the variability explained by 2 sets of variables: recycling 

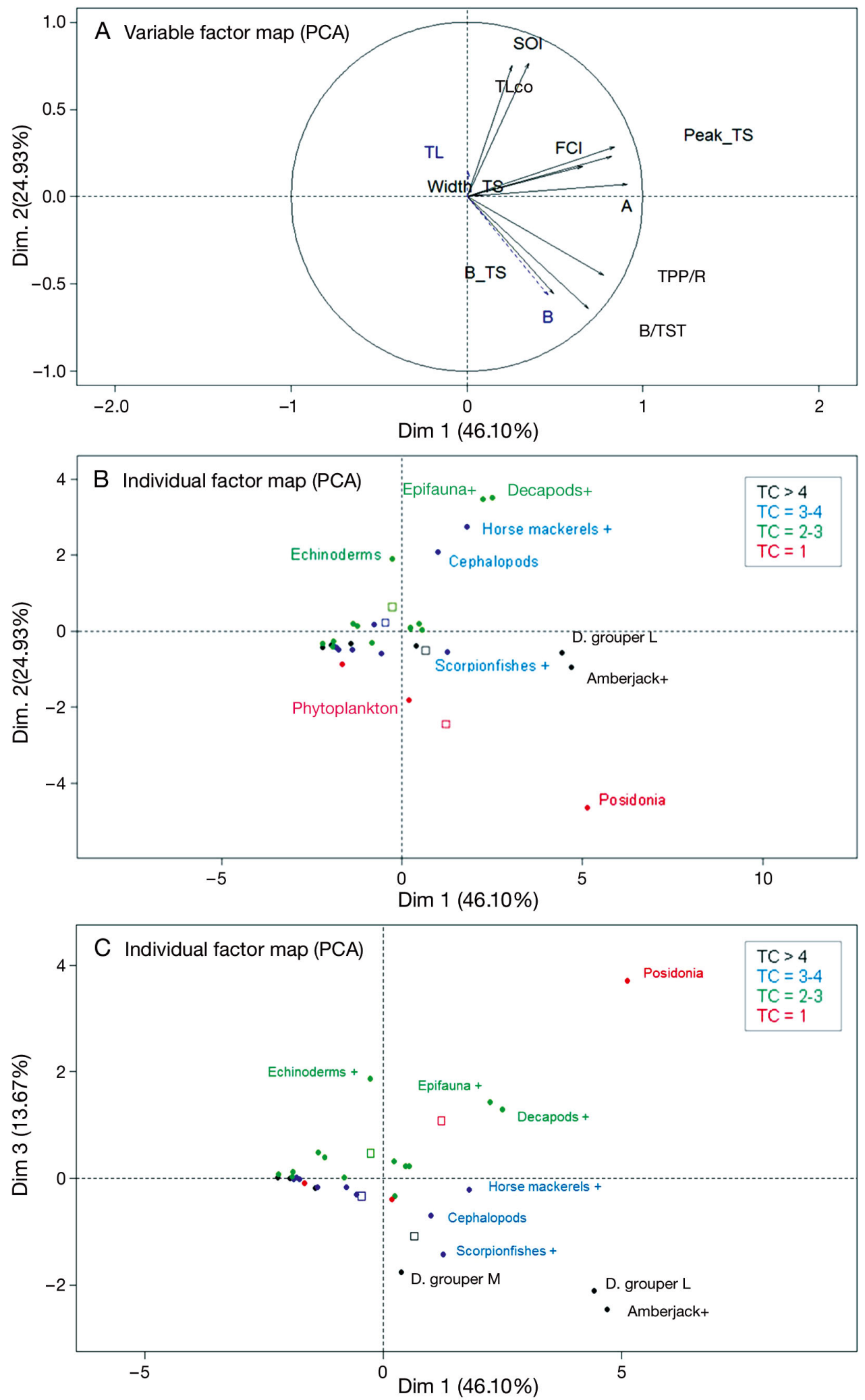

Fig. 5. Principal component analysis (PCA) plots. (A) Variables and (B) individual factors for the first 2 principal components. (C) Individual factors for principal components 1 and 3. In the variables plot (A), B and TL are the supplementary variables (blue). In the individual factor plots $(\mathrm{B}, \mathrm{C})$, only the non-overlapping points were labelled to improve visualization. B: biomass; B_TS: biomass of the trophic spectra; B/TST: biomass/total system throughput; FCI: Finn's cycling index; Peak_TS: peak of the trophic spectra; SOI: system omnivory index; TC: trophic class; $\mathrm{TL}_{\mathrm{co}}$ : mean trophic level of the community; TL: trophic level; TPP/R: total primary production/total respiration; TS: trophic spectra; Width_TS: width of the trophic spectra 
(FCI), \% A, and trophic spectra structure (Width_TS and Peak_TS) on the one hand, and the energy flux indices (TPP/R and B/TST) and trophic spectraderived biomass index (B_TS) on the other. Within each set, the variables appeared to be highly correlated to one another. The influence of the functional groups on the variables (i.e. their effect on the indices) was related to their biomass. Several species which cover the whole range of trophic levels, but with low biomass, influenced the variables less than average (Fig. 5b). In contrast, the top predators Dusky grouper - large and Amberjack+ (TL >4), having higher biomasses, strongly affected many ecosystem indices, particularly the trophic spectra indices (Width_TS, Peak_TS), ecosystem maturity (FCI, \%A), and flow indices (TPP/R, B/TST) summarized by PC1. Groups feeding on a wide range of trophic levels and with consistent biomass (Decapods, Epifaunat, Horse mackerelst and Cephalopods) affected the ecosystem complexity indices (SOI and TLco), while the Posidonia group affected the flow and biomass related indices (TPP/R,B/TST, and B_TS).

When the third PC was visualized (Fig. 5C), the functional groups were ordered by TL. Following the high TL predator groups, the Scorpionfishes+, Cephalopods, and Horse mackerels+ were arranged in decreasing order of TL and contributed equally to PC1. On the positive side of PC3, the TL of the groups decreased, and biomass became the dominant supplementary variable. Thus, Decapods+ and Epifauna+ contributed equally to both PC1 and PC3 in terms of the ecosystem complexity indices (SOI and $\mathrm{TL}_{\mathrm{co}}$ ), while Posidonia, having the highest biomass, showed the highest contribution to PC1 and PC3 in terms of overall biomass increase (B_TS), and to $\mathrm{PC} 1$ for $\% \mathrm{~A}$.

The first 3 PCs summarized approximately $80 \%$ of the variability explained by the indices, so the functional groups were ranked according to their contributions to these axes. By plotting the species in decreasing order of their mean rank (rank of 1 for the species having the highest impact) (Fig. 6), we highlighted 2 major gaps among the ranking scores. The first and most evident gap separated Posidonia, Amberjack+, Epifaunat, Decapods+ and Dusky grouper - large, which had the highest ranking on all 3 PCs, from Cephalopods. The second gap separated the Cephalopods and Horse mackerels+ from the other groups. The rankings gradually decreased after these groups, so no further groups were selected.

\section{DISCUSSION}

We have addressed 2 issues in this paper related to model uncertainty: functional group aggregation and sensitivity to biomass data input. Our intent was to improve the feasibility of Ecopath applications for complex Mediterranean coastal ecosystems by accounting for the constraints that field sampling and monitoring impose on the collection of reliable data. We evaluated how these constraints might lead to an altered description of ecosystem functioning and proposed a model structure that allows for a compromise between reliability and feasibility.

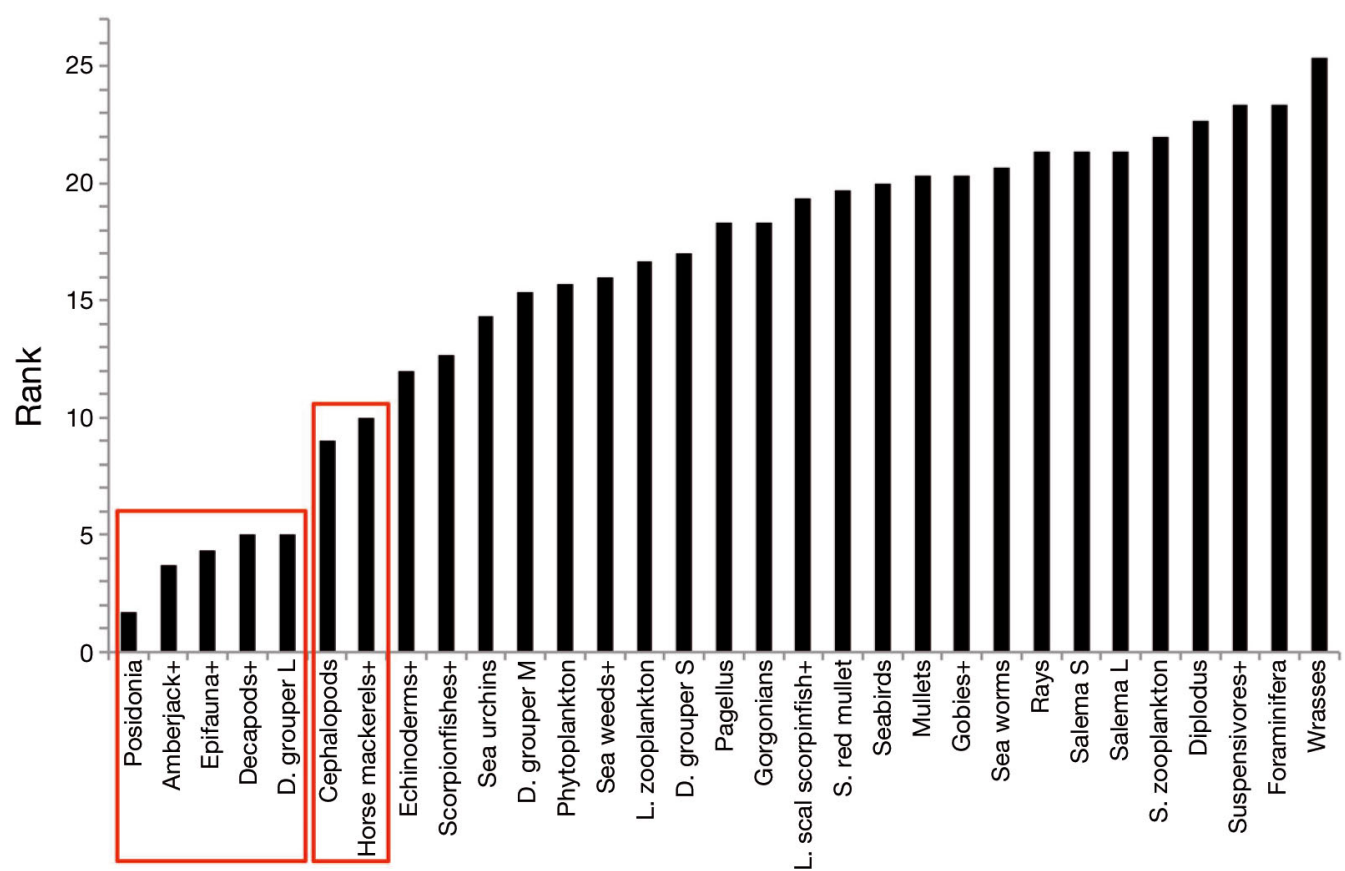

Fig. 6. Ranking of the functional groups based on their contributions to the first 3 principal components. Red boxes separate the first and second groups with the highest rankings 


\section{Aggregating trophic groups}

Initially, we dealt with the effects of aggregation on food-web properties. The issue of the ecosystem indices' dependence upon the model structure has been largely discussed in the literature. Many studies have concluded that food-web properties are affected not only by the reduction in the number of compartments, but also and primarily by the way the functional groups are aggregated in such compartments (Christensen 1995, Abarca-Arenas \& Ulanowicz 2002, Fulton et al. 2003, Pinnegar et al. 2005). Until further knowledge is obtained, models built in a standardized way, at least for similar ecosystems, could increase the reliability of model comparisons over time and/or space (Dame \& Christian 2006, Fulton 2010).

Focusing on a northwestern Mediterranean coastal ecosystem, we identified which species aggregation choices, defined on the basis of sampling efficiency considerations, caused major modifications in the model description of the ecosystem state and should therefore be avoided. We mainly focused on lower TL groups that are often less studied and overly aggregated in ecosystem models.

From our analysis, it appeared that some indices (SOI and \%A) vary significantly less than others (FCI) among the different model configurations (Fig. 1). These configurations primarily differed for the invertebrate functional groups. Pinnegar et al. (2005) tested aggregation schemes emphasizing different parts of the food web (fish, marine mammals, and invertebrates) and reported greater variation for the same 2 indices compared to our results. Nevertheless, in a recent meta-analysis on 105 food-web models from different areas of the world, \%A proved to be robust to the model construction in terms of the number of functional groups (Heymans et al. 2014). FCI showed the strongest variations among all our model configurations.

Decapods, crabs, suspensivores, and polychaetes were responsible for the main differences between the ecosystem structures described by the models. These groups show different degrees of connection within the food web in comparison to the other macrofaunal invertebrates (amphipods, small crustaceans, gastropods, and brittle stars) and have different predators (low predator overlap index). Consequently, aggregating them together increased the connections between the primary producers and the upper levels of the food web, and it introduced cannibalism within the group. By altering the feedback cycles in the model, it is likely that this pooling affects the overall stability of the system (Dambacher et al. 2003). This aggregation thus led to an erroneous and increased quantification of FCI, which might affect interpretation of the ecosystem's resilience and maturity. This result agrees with the analysis in Pinnegar et al. (2005), in which the fish-centred model, including a compartment equivalent to our epifaunal group, showed the greatest increase in FCI. In addition, SOI largely decreased, because the variety of the TLs upon which the upper consumers feed is reduced. Species interactions in the food web might thus appear less complex than they are in reality. More particularly, given the important biomass of decapods and their connections with higher TLs, their inclusion in the Epifauna group significantly altered the biomass trophic spectrum, impacting the distribution of biomass up to higher TLs and causing a general decrease in the mean TL of the community. Trophic spectra are now recognized as a useful tool with which to analyse the impacts of fisheries and/or protection on the whole trophic network (Gascuel et al. 2009, Libralato et al. 2010, Colléter et al. 2012, Lassalle et al. 2012), but if they are initially altered by a biased model structure, inaccurate conclusions could be derived from their observation. The inclusion of polychaetes and suspensivores in the Epifauna group should be avoided, although it would simplify sampling. This confirms the existing knowledge that groups accessing primarily different food sources within the system should not be overaggregated (Fulton et al. 2003, Pinnegar et al. 2005).

The groupings that did not significantly affect the model behaviour were the amphipods with small crustaceans, gastropods, and brittle stars; decapods with crabs; suspensivores with bivalves; sea stars with sea cucumbers; and grouping all small cryptobenthic fishes together (i.e. gobies, blennies, and pipefishes). Some of these results may be explained by the similar functional role of the groups (amphipods, small crustaceans, and gastropods), while others are possibly due to the very low biomass of one of the 2 groups in the control model (i.e. bivalves and sea stars). It would be interesting to compare such results with other aggregation approaches used in ecosystem modelling. The regular coloration algorithms applied in Johnson et al. (2001), for example, formalize the aggregation procedure by collapsing groups that have ties to equivalent prey and predators, with equivalent groups being those that pertain to the same TL.

The simplified trophic structure implied a substantial reduction in complexity and a simplification of the data collection process due to greater aggregation than in the control model (31 living groups instead of 40). Nevertheless, even after applying a 
simulated increase in the fishing effort, the level of aggregation did not noticeably affect the distribution of biomass across the TLs. The simplified model is still rather detailed in comparison to other models of the Mediterranean, such as the Miramare Natural Marine Reserve model (Libralato et al. 2006), which has 23 functional groups, or the Bonifacio Strait Natural Reserve model (Albouy et al. 2010), which has 31 groups.

\section{Prioritizing groups for biomass estimates}

Next, we assessed the model uncertainty related to the quality of the biomass input data. Based on Essington's conclusions on biomass input data being the parameter that most affects the model output estimations, we wanted to identify which groups our model was most sensitive to after a variation in their biomass. The most influential species we identified were all characterized by a high biomass, a high TL and a diversified diet, or a combination of the two. Abundant high TL predators, such as the large dusky grouper Epinephelus marginatus and species in the Amberjack group (including Seriola dumerili, Sphyraena viridensis, Dicentrarchus labrax, Conger conger, and Muraena helena; see Appendix 1), comprised the groups with the most impact on the trophic spectra and ecosystem maturity indices $(\% \mathrm{~A}, \mathrm{FCI}$, TPP/R, and TB/TST). Thus, inaccurate input biomass data for these groups would alter the biomass estimates of all other groups. As demonstrated by the biomass trophic spectra, higher prey biomass would be required to sustain a higher biomass for these predators, consequently affecting the trophic structure of the ecosystem. Our results were similar to Christensen \& Pauly's (1998) simulations, where the top predators' biomass was increased to assess the carrying capacity of an ecosystem. A 10-fold increase in the top predators' biomass, given a fixed primary production, increased FCI and TPP/R approached 1, meaning less sedimentation, better utilization of the detritus, and nutrient recycling within the food web, which corresponds to an image of a more mature system sensu Odum (1969). Our results on the influence of high TL predators on food-web properties are in accordance with the general knowledge that these predators are good indicators of ecosystem health and maturity (Ray et al. 2005, Prato et al. 2013), and their recovery in a protected zone is the first sign of improved ecosystem health (Sandin \& Sala 2012). As we demonstrated, models built with inaccurate biomass data for high TL predators and fixed primary producer values would depict a significantly altered food web.

Epifauna, Decapods+, Horse mackerels+, and Cephalopods were the groups that most influenced the ecosystem complexity by modifying the SOI and the mean TL of the community. Epifauna and decapods are abundant in the ecosystem and are the main prey items of many other groups (high ecotrophic efficiencies), and therefore act as connectors between the primary producers and the upper TLs. The planktivorous fish group (including horse mackerels, Chromis chromis, Spicara spp., Boops boops, and Oblada melanura) and cephalopods significantly affected the biomass trophic spectra, causing biased biomass estimates for a wide range of functional groups. Indeed, planktivorous fish represent up to $32 \%$ of fish biomass and are responsible for up to $40 \%$ of all fish throughput in some Mediterranean ecosystems (Pinnegar \& Polunin 2004). These fishes are important prey for coastal predators, as well as important detritus producers (Pinnegar 2000, Pinnegar \& Polunin 2004). They may also be involved in wasp-waist control mechanisms, similar to those in the South Catalan Sea (Coll et al. 2006). Cephalopods have high consumption rates (the highest among all upper TLs), a widely diversified diet, and are a preferred prey for many predatory fish. Thus, this group is very likely playing a significant role in the energy and material flow of marine ecosystems (Coll et al. 2013b). However, it is often difficult to assess their abundance and role in marine ecosystems, primarily due to logistical problems (Piatkowski et al. 2001).

The strong influence of Posidonia oceanica on the maturity indices related to flow measures was probably due to its high biomass, which was an order of magnitude greater than any other functional group. Moreover, given the low consumption rate of $P$. oceanica by other functional groups (low ecotrophic efficiency), an increase in its biomass might cause an increased flow to detritus, thereby affecting FCI.

Our study was based on the single example of the Port-Cros ecosystem, for which a large amount of information was available. Nonetheless, useful insights can be derived from an in-depth analysis of a well-known complex food web and applied to comparable ecosystems (i.e. northwestern Mediterranean) (Sala 2004).

The identification of high TL predators and $P$. oceanica as the most influential groups in our study is in agreement with Mediterranean monitoring programs (Moreno et al. 2001, Levin \& Grimes 2002, Coll et al. 2008, Montefalcone 2009, Di Franco et al. 2009, Prato et al. 2013). Nevertheless, accurate methods to 
assess their biomass are still a challenging issue, especially for high TL predators. In addition to these groups, our results highlighted the important role in the food web of groups that are usually poorly detailed, such as epifauna, decapods, planktivorous fish, and cephalopods. Although the importance of these groups has been demonstrated in Mediterranean coastal ecosystems (Sala 1997, Pinnegar 2000, Piatkowski et al. 2001, Goñi et al. 2006), they are rarely included in monitoring programs for many reasons, e.g. the challenges in obtaining good quality data, the absence of commercial value or of a protection status, and the lack of public awareness for noncharismatic species.

\section{CONCLUSIONS}

Food-web modelling enables setting reference levels for indicators of ecosystem structure and functioning (Dame \& Christian 2006, Heymans et al. 2014), which is very useful in the context of the ecosystem approach to marine resource management. In this study, we showed that ecosystem indicators largely depend on model structure and that the reliability of the reference levels for the ecosystem indicators may be improved by developing standardized models that account for input data quality.

We identified a level of trophic aggregation that simplifies the model structure and data collection, without significantly altering the model results. The priority functional groups requiring accurate biomass estimates were also identified (Dusky grouper large, Amberjack+, Posidonia oceanica, Decapods+, Epifaunat, Horse mackerelst, and Cephalopods). Link et al. (2012) stated that if the component of model uncertainty linked to observation error needs to be overcome, sampling designs should be improved in a cost-effective way; priority should be given to increasing the data accuracy for poorly known components of the food web, rather than adding further precision to already well-known groups. However, we should acknowledge that obtaining accurate biomass data for all functional groups is not always feasible in complex and highly diverse Mediterranean coastal ecosystems. Thus, we suggest focusing on better documenting the biomass of the poorly known but important groups (such as those we identified), which could help to increase the reliability of the Ecopath-standardized applications in such complex ecosystems.

The methodological approach proposed here to address the issue of model simplification is of interest for 2 reasons: (1) it increases the feasibility of model building in terms of data collection; and (2) it adds to our knowledge of the modelled system by analysing the effects of simplification and imprecise biomass data on the ecosystem indices, trophic structure, and the capacity of the model to assess fishery impacts. This approach is easily applicable, and it could help foster the development of standardized Ecopath models to represent complex Mediterranean food webs.

Acknowledgements. The present study was supported by the MMMPA - Training Network for Monitoring Mediterranean Marine Protected Areas, which has received funding from the European Community's Seventh Framework Programme (FP7/2007-2013) under Grant Agreement no. 290056. A.V. acknowledges support from the Nereus - Predicting the Future Ocean Program, a scientific cooperation between the Nippon Foundation and UBC with four additional partners. Many thanks are expressed to the anonymous reviewers for helpful comments on an early draft of this manuscript.

\section{LITERATURE CITED}

Abarca-Arenas LG, Ulanowicz RE (2002) The effects of taxonomic aggregation on network analysis. Ecol Model 149:285-296

Albouy C, Mouillot D, Rocklin D, Culioli J, Le Loc'h F (2010) Simulation of the combined effects of artisanal and recreational fisheries on a Mediterranean MPA ecosystem using a trophic model. Mar Ecol Prog Ser 412:207-221

Barausse A, Duci A, Mazzoldi C, Artioli Y, Palmeri L (2009) Trophic network model of the Northern Adriatic Sea: analysis of an exploited and eutrophic ecosystem. Estuar Coast Shelf Sci 83:577-590

Bayle-Sempere JT, Arreguín-Sánchez F, Sanchez-Jerez P, Salcido-Guevara LA, Fernandez-Jover D, Zetina-Rejón MJ (2013) Trophic structure and energy fluxes around a Mediterranean fish farm. Ecol Model 248:135-147

Botsford LW, Castilla JC, Peterson CH (1997) The management of fisheries and marine ecosystems. Science 277: 509-515

Brando VE, Ceccarelli R, Libralato S, Ravagnan G (2004) Assessment of environmental management effects in a shallow water basin using mass-balance models. Ecol Model 172:213-232

Carrer S, Opitz S (1999) Trophic network model of a shallow water area in the northern part of the Lagoon of Venice. Ecol Model 124:193-219

> Christensen V (1994) On the behavior of some proposed goal functions for ecosystem development. Ecol Model 75-76:37-49

> Christensen V (1995) Ecosystem maturity—towards quantification. Ecol Model 77:3-32

- Christensen V, Pauly D (1992) Ecopath II-a software for balancing steady-state ecosystem models and calculating network characteristics. Ecol Model 61:169-185

> Christensen V, Pauly D (1998) Changes in models of aquatic ecosystems approaching carrying capacity. Ecol Appl 8: S104-S109

> Christensen V, Walters CJ (2004) Ecopath with Ecosim: methods, capabilities and limitations. Ecol Model 172: 109-139 
Christensen V, Walters CJ (2005) Using ecosystem modeling for fisheries management: where are we. ICES CM / M:19

Christensen V, Walters CJ, Pauly D, Forrest R (2008). Ecopath with Ecosim version 6 user guide. Lenfest Ocean Futures Project, University of British Columbia, Vancouver

Coll M, Libralato S (2012) Contributions of food web modelling to the ecosystem approach to marine resource management in the Mediterranean Sea. Fish Fish 13:60-88

Coll M, Palomera I, Tudela S, Sardà F (2006) Trophic flows, ecosystem structure and fishing impacts in the South Catalan Sea, northwestern Mediterranean. J Mar Syst 59:63-96

Coll M, Lotze HK, Romanuk TN (2008) Structural degradation in Mediterranean Sea food webs: testing ecological hypotheses using stochastic and mass-balance modelling. Ecosystems 11:939-960

$>$ Coll M, Cury P, Azzurro E, Bariche M and others (2013a) The scientific strategy needed to promote a regional ecosystem-based approach to fisheries in the Mediterranean and Black Seas. Rev Fish Biol Fish 23:415-434

Coll M, Navarro J, Olson RJ, Christensen V (2013b) Assessing the trophic position and ecological role of squids in marine ecosystems by means of food-web models. Deep-Sea Res II 95:21-36

Colléter M, Gascuel D, Ecoutin JM, Tito de Morais L (2012) Modelling trophic flows in ecosystems to assess the efficiency of marine protected area (MPA), a case study on the coast of Senegal. Ecol Model 232:1-13

Colléter M, Guitton J, Gascuel D (2013) An introduction to the EcoTroph R package: analyzing aquatic ecosystem trophic networks. R Journal 5:98-107

Dambacher JM, Luh H, Li HW, Rossignol PA (2003) Qualitative stability and ambiguity in model ecosystems. Am Nat 161:876-888

Dame JK, Christian RR (2006) Uncertainty and the use of network analysis for ecosystem-based fishery management. Fisheries 31:331-341

Daskalov GM (2002) Overfishing drives a trophic cascade in the Black Sea. Mar Ecol Prog Ser 225:53-63

> Di Franco A, Bussotti S, Navone A, Panzalis P, Guidetti P (2009) Evaluating effects of total and partial restrictions to fishing on Mediterranean rocky-reef fish assemblages. Mar Ecol Prog Ser 387:275-285

Díaz López B, Bunke M, Bernal Shirai JA (2008) Marine aquaculture off Sardinia Island (Italy): ecosystem effects evaluated through a trophic mass-balance model. Ecol Model 212:292-303

Espinoza-Tenorio A, Wolff M, Taylor MH, Espejel I (2012) What model suits ecosystem-based fisheries management? A plea for a structured modeling process. Rev Fish Biol Fish 22:81-94

Essington TE (2007) Evaluating the sensitivity of a trophic mass-balance model (Ecopath) to imprecise data inputs. Can J Fish Aquat Sci 64:628-637

Francour P (1990) Dynamique de l'écosystème à Posidonia oceanica dans le Parc National de Port-Cros. Analyse des compartiments matte, litière, faune vagile, échinodermes et poissons. $\mathrm{PhD}$ thesis, Université Pierre et Marie Curie, Paris

- Francour P, Harmelin JG, Pollard D, Sartoretto S (2001) A review of marine protected areas in the northwestern Mediterranean region: siting, usage, zonation and management. Aquat Conserv Mar Freshw Ecosyst 11: 155-188
Fulton EA (2010) Approaches to end-to-end ecosystem models. J Mar Syst 81:171-183

Fulton EA, Smith ADM, Johnson CR (2003) Effect of complexity on marine ecosystem models. Mar Ecol Prog Ser 253:1-16

Gasche L, Gascuel D (2013) EcoTroph: a simple model to assess fishery interactions and their impacts on ecosystems. ICES J Mar Sci 70:498-510

> Gascuel D (2005) The trophic-level based model: a theoretical approach of fishing effects on marine ecosystems. Ecol Model 189:315-332

- Gascuel D, Bozec YM, Chassot E, Colomb A, Laurans M (2005) The trophic spectrum: theory and application as an ecosystem indicator. ICES J Mar Sci 62:443-452

- Gascuel D, Pauly D (2009) EcoTroph: modelling marine ecosystem functioning and impact of fishing. Ecol Model 220:2885-2898

Gascuel D, Tremblay-Boyer L, Pauly D (2009) EcoTroph (ET): a trophic level based software for assessing the impacts of fishing on aquatic ecosystems. Res Rep 17, Fisheries Centre, University of British Columbia, Canada

> Gascuel D, Guénette S, Pauly D (2011) The trophic-levelbased ecosystem modelling approach: theoretical overview and practical uses. ICES J Mar Sci 68:1403-1416

> Goñi R, Quetglas A, Reñones O (2006) Spillover of spiny lobsters Palinurus elephas from a marine reserve to an adjoining fishery. Mar Ecol Prog Ser 308:207-219

Gucu AC (2002) Can overfishing be responsible for the successful establishment of Mnemiopsis leidyi in the Black Sea? Estuar Coast Shelf Sci 54:439-451

- Guénette S, Meissa B, Gascuel D (2014) Assessing the contribution of marine protected areas to the trophic functioning of ecosystems: a model for the Banc d'Arguin and the Mauritanian Shelf. PLoS ONE 9:e94742

Guidetti P (2007) Predator diversity and density affect levels of predation upon strongly interactive species in temperate rocky reefs. Oecologia 154:513-520

Heymans JJ, Coll M, Libralato S, Morissette L, Christensen $\mathrm{V}$ (2014) Global patterns in ecological indicators of marine food webs: a modelling approach. PLoS ONE 9: e95845

Hofmann EE, Powell TM (1998) Environmental variability effects on marine fisheries: four case histories. Ecol Appl 8:S23-S32

Johnson JC, Borgatti SP, Luczkovich JJ, Everett MG (2001) Network role analysis in the study of food webs: an application of regular role coloration. J Social Struct 2: $1-15$

Johnson GA, Niquil N, Asmus H, Bacher C, Asmus R, Baird D (2009) The effects of aggregation on the performance of the inverse method and indicators of network analysis. Ecol Model 220:3448-3464

Kearney KA, Stock C, Sarmiento JL (2013) Amplification and attenuation of increased primary production in a marine food web. Mar Ecol Prog Ser 491:1-14

Khoury C (1987) Ichtyofaune des herbiers de posidonies du Parc National de Port-Cros: composition, éthologie alimentaire et rôle dans le réseau trophique. PhD thesis, Université Aix-Marseille II, France

> Lassalle G, Gascuel D, Le Loc'h F, Lobry J and others (2012) Assessing the effects of fisheries on marine top predators: the Bay of Biscay case study. ICES J Mar Sci 69: 925-938

Levin PS, Grimes CB (2002) Reef fish ecology and grouper conservation and management. In: Sale PF (ed) Coral 
reef fishes: dynamics and diversity in a complex ecosystem. Academic Press, San Diego, CA, p 377-390

Libralato S, Pastres R, Pranovi F, Raicevich S, Granzotto A, Giovanardi O, Torricelli P (2002) Comparison between the energy flow networks of two habitats in the Venice Lagoon. Mar Ecol 23:228-236

Libralato S, Tempesta M, Solidoro C, Spoto M (2006) An ecosystem model applied to Miramare natural marine reserve: limits, advantages and perspectives. Biol Mar Mediterr 13:386-395

Libralato S, Coll M, Tempesta M, Santojanni A and others (2010) Food-web traits of protected and exploited areas of the Adriatic Sea. Biol Conserv 143:2182-2194

Link JS (2010) Adding rigor to ecological network models by evaluating a set of pre-balance diagnostics: a plea for PREBAL. Ecol Model 221:1580-1591

Link JS, Ihde TF, Harvey CJ, Gaichas SK and others (2012) Dealing with uncertainty in ecosystem models: the paradox of use for living marine resource management. Prog Oceanogr 102:102-114

Montefalcone M (2009) Ecosystem health assessment using the Mediterranean seagrass Posidonia oceanica: a review. Ecol Indic 9:595-604

Moreno D, Aguilera PA, Castro H (2001) Assessment of the conservation status of seagrass (Posidonia oceanica) meadows: implications for monitoring strategy and the decision-making process. Biol Conserv 102:325-332

Moutopoulos DK, Libralato S, Solidoro C, Stergiou KI (2013) Toward an ecosystem approach to fisheries in the Mediterranean Sea: multi-gear/multi-species implications from an ecosystem model of the Greek Ionian Sea. J Mar Syst 113-114:13-28

> Odum EP (1969) The strategy of ecosystem development. Science 164:262-270

Palomares MLD, Reyes-Marchant P, Zainure L, Barnabe G, Lasserre G (1993) A trophic model of a Mediterranean lagoon, Etang de Thau, France. In: Christensen V, Pauly D (eds), Trophic models of aquatic ecosystems. ICLARM Conf Proc 26:153-158

Pauly D, Bartz MS, Palomares MLD (1993) Improved construction, parametrization and interpretation of steadystate ecosystem models. In: ICLARM Conf Proc 26: 224-229

Pauly D, Christensen V, Walters C (2000) Ecopath, Ecosim, and Ecospace as tools for evaluating ecosystem impact of fisheries. ICES J Mar Sci 57:697-706

Piatkowski U, Pierce GJ, Morais da Cunha M (2001) Impact of cephalopods in the food chain and their interaction with the environment and fisheries: an overview. Fish Res 52:5-10

Pinnegar JK (2000) Planktivorous fishes: links between the Mediterranean littoral and pelagic. PhD thesis, University of Newcastle, UK

Pinnegar JK, Polunin NVC (2004) Predicting indirect effects of fishing in Mediterranean rocky littoral communities using a dynamic simulation model. Ecol Model 172: 249-267

Pinnegar JK, Blanchard JL, Mackinson S, Scott RD, Duplisea DE (2005) Aggregation and removal of weak-links in food-web models: system stability and recovery from disturbance. Ecol Model 184:229-248

Plagányi ÉE (2007) Models for an ecosystem approach to fisheries. Fish Tech Pap 477, FAO, Rome

Polovina JJ (1984) Model of a coral reef ecosystem. Coral Reefs 3:1-11
Piroddi C, Giovanni B, Christensen V (2010) Effects of local fisheries and ocean productivity on the northeastern Ionian Sea ecosystem. Ecol Model 221:1526-1544

Pranovi F, Link JS (2009) Ecosystem exploitation and trophodynamic indicators: a comparison between the northern Adriatic Sea and southern New England. Prog Oceanogr 81:149-164

Pranovi F, Libralato S, Raicevich S, Granzotto A, Pastres R, Giovanardi O (2003) Mechanical clam dredging in Venice Lagoon: ecosystem effects evaluated with a trophic mass-balance model. Mar Biol 143:393-403

Prato G, Guidetti P, Bartolini F, Mangialajo L, Francour P (2013) The importance of high-level predators in marine protected area management: consequences of their decline and their potential recovery in the Mediterranean context. Adv Oceanogr Limnol 4:176-193

Punt AE, Butterworth DS (1995) The effects of future consumption by the Cape fur seal on catches and catch rates of the Cape hakes. 4. Modelling the biological interaction between Cape fur seals Arctocephalus pusillus pusillus and the Cape hakes Merluccius capensis and $M$. paradoxus. S Afr J Mar Sci 16:255-285

Ray J, Redford KH, Steneck R, Berger J (2005) Large carnivores and the conservation of biodiversity. Island Press, Washington, DC

Sala E (1997) The role of fishes in the organization of a Mediterranean sublittoral community. II. Epifaunal communities. J Exp Mar Biol Ecol 212:45-60

Sala E (2004) The past and present topology and structure of Mediterranean subtidal rocky-shore food webs. Ecosystems 7:333-340

> Sala E, Boudouresque CF, Harmelin-Vivien M (1998) Fishing, trophic cascades, and the structure of algal assemblages: evaluation of an old but untested paradigm. Oikos 82:425-439

Sandin SA, Sala E (2012) Using successional theory to measure marine ecosystem health. Evol Ecol 26:435-448

Tsagarakis K, Coll M, Giannoulaki M, Somarakis S, Papaconstantinou C, Machias A (2010) Food-web traits of the North Aegean Sea ecosystem (eastern Mediterranean) and comparison with other Mediterranean ecosystems. Estuar Coast Shelf Sci 88:233-248

> Ulanowicz RE, Norden JS (1990) Symmetrical overhead in flow networks. Int J Syst Sci 21:429-437

> Valls A, Gascuel D, Guénette S, Francour P (2012) Modeling trophic interactions to assess the effects of a marine protected area: case study in the NW Mediterranean Sea. Mar Ecol Prog Ser 456:201-214

Vasconcellos M, Mackinson S, Sloman K, Pauly D (1997) The stability of trophic mass-balance models of marine ecosystems: a comparative analysis. Ecol Model 100:125-134

Walters C, Christensen V, Pauly D (1997) Structuring dynamic models of exploited ecosystems from trophic mass-balance assessments. Rev Fish Biol Fish 7:139-172

> Walters C, Pauly D, Christensen V (1999) Ecospace: prediction of mesoscale spatial patterns in trophic relationships of exploited ecosystems, with emphasis on the impacts of marine protected areas. Ecosystems 2:539-554

Yodzis P (2001) Must top predators be culled for the sake of fisheries? Trends Ecol Evol 16:78-84

Zucchetta M, Libralato S, Granzotto A, Pranovi F, Raicevich S (2003) Modelling approach for the evaluation of the efficacy of MPA in the northern Adriatic Sea. In: Özhan E (ed) Proc 6th Int Conf Mediterranean Coast Environ, MEDCOAST, Ravenna, Vol 3, p 433-444 


\begin{tabular}{|c|c|}
\hline 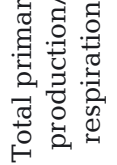 & 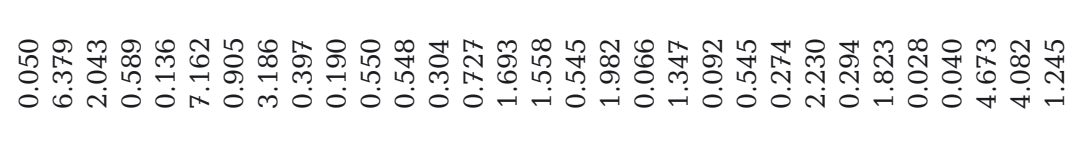 \\
\hline 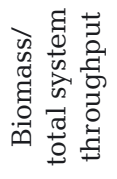 & 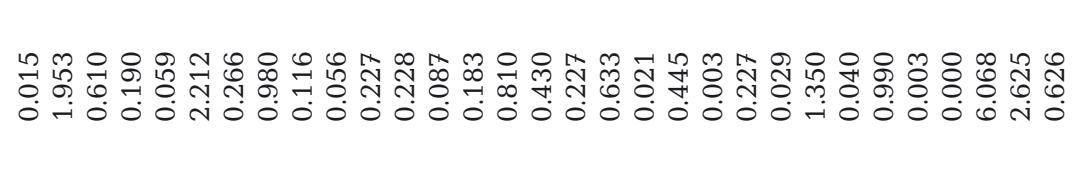 \\
\hline 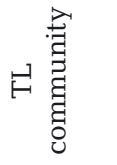 & 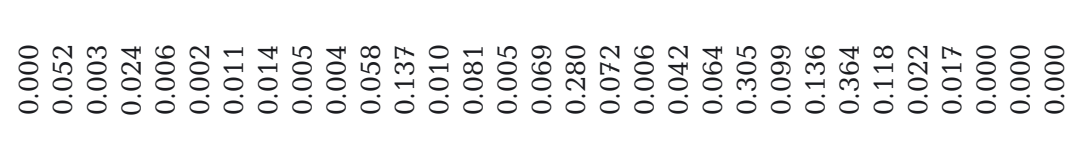 \\
\hline 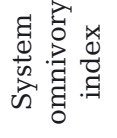 & 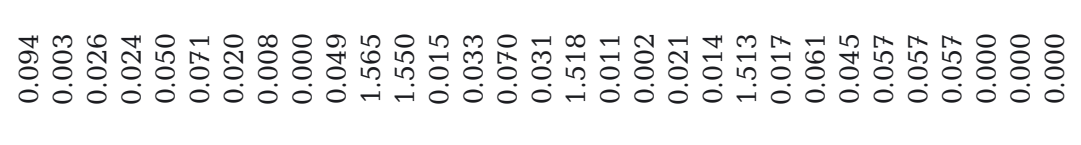 \\
\hline 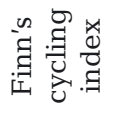 & 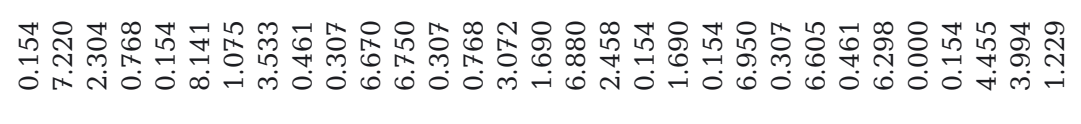 \\
\hline 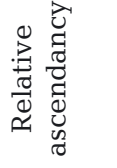 & 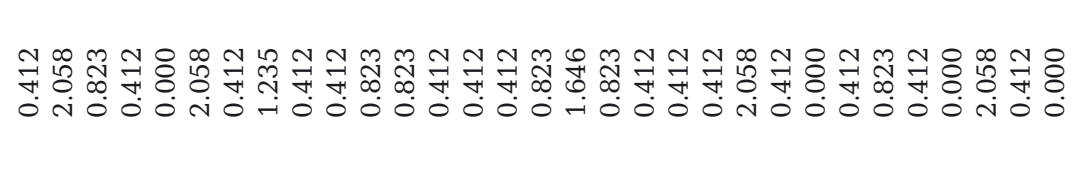 \\
\hline 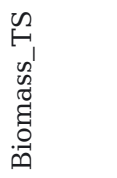 & 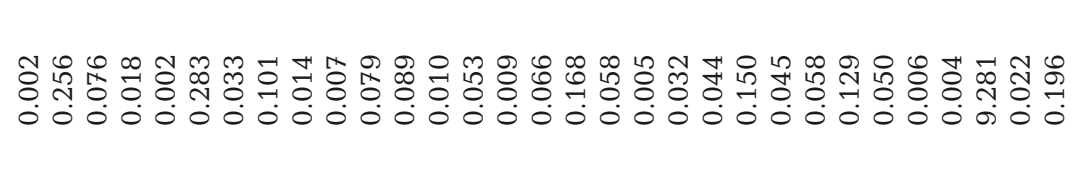 \\
\hline 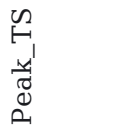 & 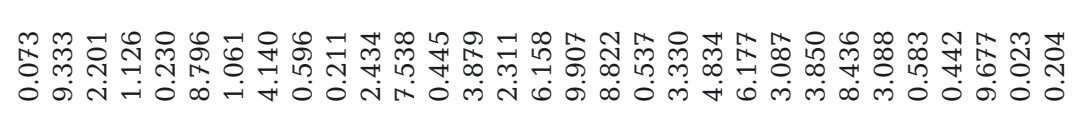 \\
\hline 足 & 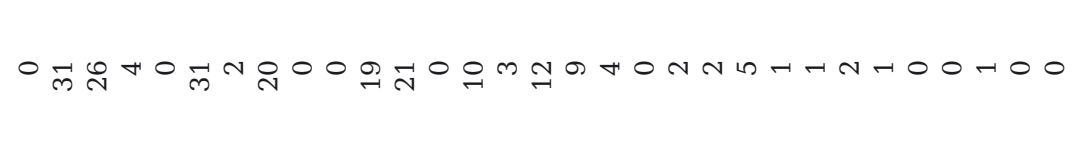 \\
\hline 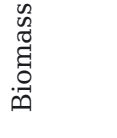 & 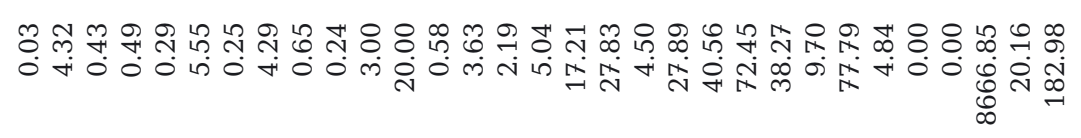 \\
\hline 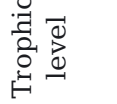 & 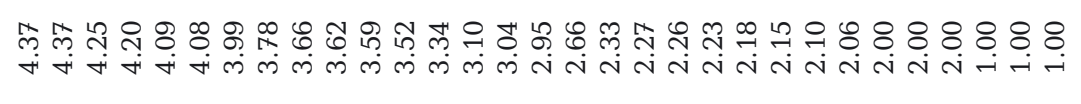 \\
\hline 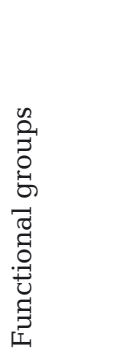 & 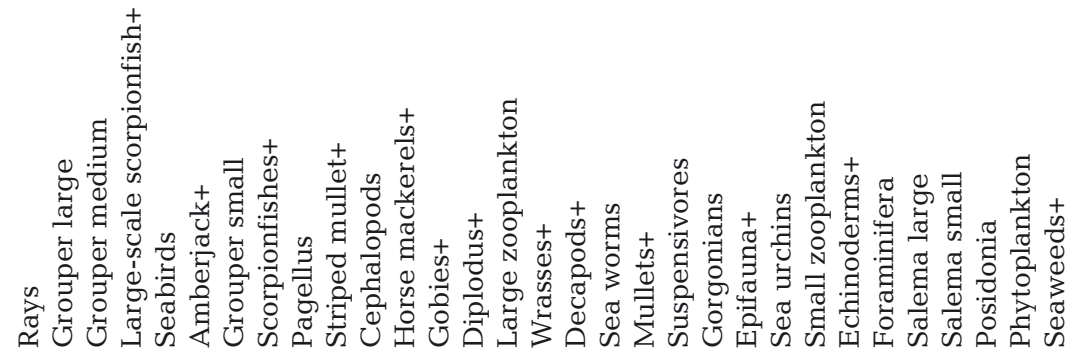 \\
\hline
\end{tabular}

